\title{
Controversies in the management of hyperglycaemic emergencies in adults with diabetes
}

\author{
Luís Cardoso $^{a, *}$, Nuno Vicente ${ }^{a}$, Dírcea Rodrigues ${ }^{a, b}$, Leonor Gomes ${ }^{a, b}$, Francisco Carrilho $^{a}$ \\ a Department of Endocrinology, Diabetes and Metabolism, Centro Hospitalar e Universitário de Coimbra, Coimbra, Portugal \\ ${ }^{\mathrm{b}}$ Faculty of Medicine, University of Coimbra, Coimbra, Portugal
}

\section{A R T I C L E I N F O}

Article history:

Received 29 September 2016

Accepted 22 November 2016

Keywords:

Diabetes

Hyperglycaemic emergencies

Acute diabetes complications

Diabetic ketoacidosis

Hyperglycaemic hyperosmolar syndrome

\begin{abstract}
A B S T R A C T
Hyperglycaemic emergencies are associated with significant morbi-mortality and healthcare costs. Management consists on fluid replacement, insulin therapy, and electrolyte correction. However, some areas of patient management remain debatable. In patients without respiratory failure or haemodynamic instability, arterial and venous $\mathrm{pH}$ and bicarbonate measurements are comparable. Fluid choice varies upon replenishment phase and patient's condition. If patient is severely hypovolaemic, normal saline solution should be the first option. However, if patient has mild/moderate dehydration, fluid choice must take in consideration sodium concentration. Insulin therapy should be guided by $\beta$-hydroxybutyrate normalization and not by blood glucose. Variations of conventional insulin infusion protocols emerged recently. Priming dose of insulin may not be required, and fixed rate insulin infusion represents the best option to suppress hepatic glucose production, ketogenesis, and lipolysis. Concomitant administration of basal insulin analogues with regular insulin infusion accelerates ketoacidosis resolution and prevents rebound hyperglycaemia. Simpler protocols using subcutaneous rapid-acting insulin analogues for mild/ moderate diabetic ketoacidosis treatment have proven to be safe and effective, but further studies are required to confirm these results. Treatment with bicarbonate, phosphate, and low-molecularweight heparin is still disputable, and randomized controlled trials are urgently needed to optimize patient management and decrease the morbi-mortality of hyperglycaemic emergencies.

(c) 2016 Elsevier Inc. All rights reserved.
\end{abstract}

\section{Introduction}

In 1828, von Stosch recognized diabetic coma as a separate entity and coined the first known clinical description [1]. Also in the first half of XIX century, William Prout accurately described hyperglycaemic emergencies, particularly the forms of diabetic coma [2]. In 1874, Kussmaul described the "air hunger" of advanced diabetic ketoacidosis,

\footnotetext{
* Corresponding author at: Department of Endocrinology, Diabetes and Metabolism, Centro Hospitalar e Universitário de Coimbra, Praceta Prof. Mota Pinto, 3000-075 Coimbra, Portugal. Tel.: +351 239400423; fax: +351 239825879 .

E-mail address: mkcardoso@gmail.com (L. Cardoso).
}

nowadays known for his eponym [3]. Twelve years later, Julius Dreschfeld delivered the Bradshaw Lecture on Diabetic Coma before the Royal College of Physicians of London, where he distinguished two forms of hyperglycaemic emergencies [4]. One, the diabetes of stout people, coma affected patients older than 40 years, who had suffered symptoms of diabetes for some time, but were still well-nourished and stout at the time of coma. No ketones were found in urine. In the other form, diabetic coma was accompanied by ketones in urine and was characterized by dyspnoea, severe gastric pain, and vomiting. Patients' breath and urine had a characteristically odor of acetone.

Even today diabetic ketoacidosis (DKA) and hyperglycaemic hyperosmolar syndrome (HHS) are potentially fatal. In the USA, 
mortality of hyperglycaemic crisis has decreased from 3012 cases in 1980 to a nadir of 2274 in 2004 . However, since then, we are facing an increase, and in 2009 there were 2417 cases reported [5]. Before insulin discovery, mortality rate of DKA virtually approached $100 \%$. Nowadays, DKA mortality rate is less than $1 \%$ in adults, but higher rates are found in developing countries, older patients, and with severe comorbidities $[6,7]$. Additionally, the risk of death increases with the number of DKA admissions. A single, 2-5, and more than 5 lifetime DKA admissions were associated with a $5.2 \%, 13.5 \%$, and $23.4 \%$ risk of death during the median follow-up period of $4.1,3.7$, and 2.4 years, respectively [8]. Despite the impressive decrease in mortality seen in the last decades, almost $40 \%$ of patients with newly diagnosed type 1 diabetes have DKA at presentation [9]. HHS causes approximately $1 \%$ of all urgent diabetes admissions, but the lack of population-based studies hinders the real estimation of HHS incidence [10]. Although more frequent in older patients, $20 \%$ of HHS cases occur before the age of 30 , and women account for up to $70 \%$ of cases [11,12]. HHS is the most dangerous acute complication of diabetes with a mortality rate of $5-20 \%[12,13]$.

HHS and DKA represent extremes of the same continuum, with different levels of insulin deficiency, dehydration, ketosis, and metabolic acidosis (Table 1 and Fig. 1) [14]. Indeed, both entities may coexist in one-third of the cases. The purpose of this review is to highlight the most recent research and provide clinical guidance, where feasible, on the controversies in the management of hyperglycaemic emergencies in adults.

\section{Laboratory Testing}

\section{1. $\quad p H$ and Bicarbonate Measurements}

Initial laboratory evaluation includes arterial blood gas sampling for measurement of $\mathrm{pH}$ and bicarbonate, and then $\mathrm{pH}$ rechecking every $2-4 \mathrm{~h}$ until stabilization (Fig. 2) [14]. There is growing evidence that arterial and venous samples may have sufficient agreement to be clinical interchangeable in DKA patients without respiratory failure or haemodynamic instability $[15,16]$. Brandenburg and Dire reported a mean difference between arterial and venous $\mathrm{pH}$ values of 0.03 and a high correlation between venous and arterial samples for $\mathrm{pH}(\mathrm{r}=0.97)$ and bicarbonate $(\mathrm{r}=0.95)$ [15]. Gokel et al. found a mean difference between arterial and venous $\mathrm{pH}$ values of 0.05 with high correlation $(r=0.99)$ in DKA patients [16]. Ma et al. showed that venous and arterial samples have good agreement, and decisions on diagnosis, treatment, or disposition in suspected DKA based on venous blood, instead of arterial blood gas, were similar [17]. Electrolytes correlation between arterial and venous blood is more complex. There are studies reporting poor agreement or unacceptable clinically differences between potassium levels in blood gas and serum samples, thus precluding the clinical interchange of these tests $[18,19]$.

\section{2. $\boldsymbol{\beta}$-Hydroxybutyrate}

Acidosis in DKA results primarily from accumulation of $\beta$ hydroxybutyrate and acetoacetate; though other acids may also have minor contributions. Acetone is present at high concentrations in DKA, but doesn't contribute to acidosis since it doesn't dissociate to yield hydrogen ions. Urine dipstick tests relie in nitroprusside reaction and reflect, in a semi-quantitative manner, the presence of acetoacetate and also acetone if glycine is added to reagent's test; however, it doesn't identify $\beta$-hydroxybutyrate. In the physiological state there is $1: 1$ proportion of $\beta$-hydroxybutyrate:acetoacetate, but during DKA the relationship raises up to 10:1. Besides not identifying the most abundant ketone body, urine dipstick tests fail to monitor response to therapy, and ketone bodies may be found in urine long after blood concentrations have normalized. Indeed, Umpierrez et al. showed that urinary nitroprusside test may remain positive after $24 \mathrm{~h}$ of insulin therapy and for more than $24 \mathrm{~h}$ after DKA resolution [20]. As DKA improves with insulin therapy, ketone bodies production decreases and conversion of $\beta$-hydroxybutyrate to acetoacetate increases, which may result in positive nitroprusside reaction

Table 1 - Diagnostic criteria of hyperglycaemic emergencies (from Kitabchi et al. [14]).

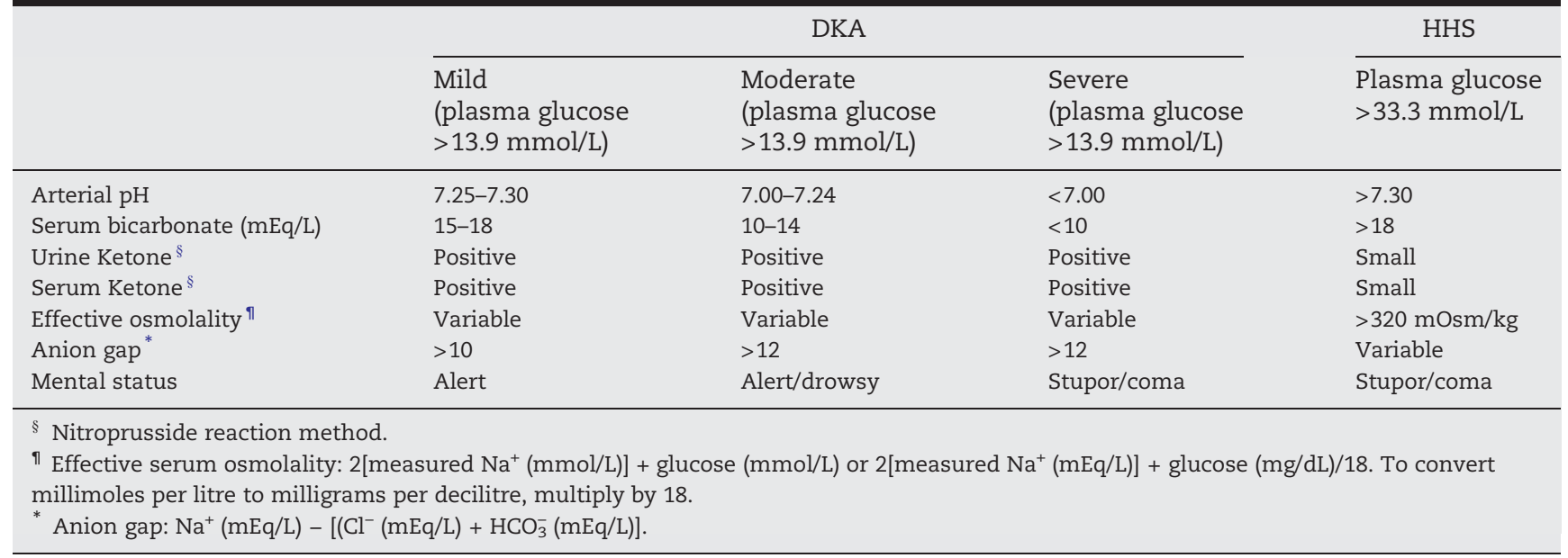




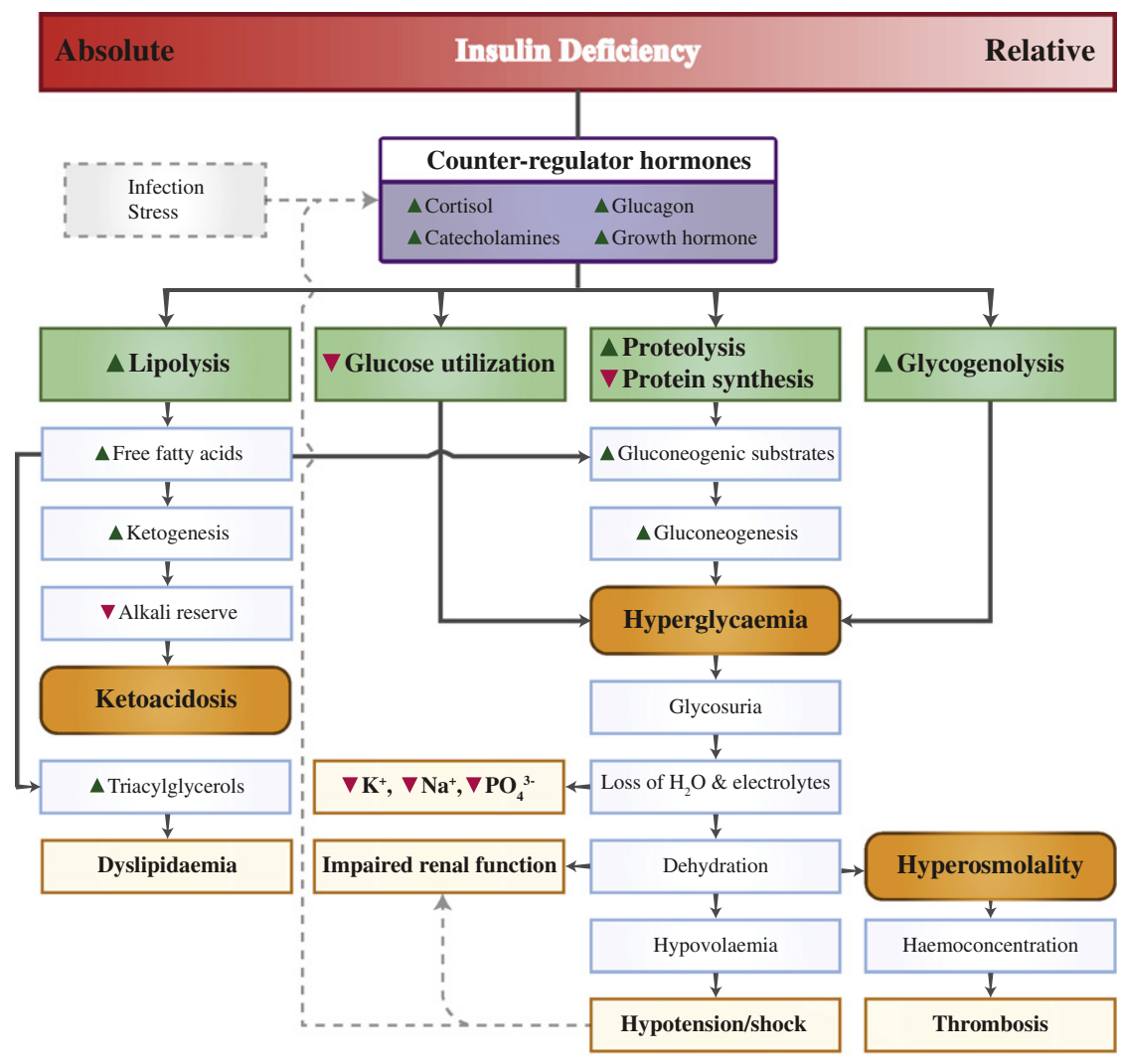

DKA

HHS

Fig. 1 - Pathophysiology of hyperglycaemic emergencies.

(urine or blood) despite low levels of $\beta$-hydroxybutyrate. Evaluation of ketone bodies in urine of highly dehydrated patients, that may not urinate spontaneously for several hours, poses another challenge. False-positive readings occur in the presence of sulfhydryl-containing drugs, like captopril, N-acetylcysteine, or penicillamine [21]. Ketonuria occurs in up to $20 \%$ of normal pregnant women after an overnight fast. Indeed, pregnancy increases maternal ketone bodies by a factor of 2-3 [22]. Levodopa metabolites may also give falsepositive readings [23]. False-negative results may occur when tests strips have been exposed to air for long time or in the presence of high acidic urine, for instance after intake of large amounts of ascorbic acid [24].

Development of laboratorial tests based on blood $\beta$ hydroxybutyrate concentrations resolved most of these issues. These quantitative tests avoid false-positive readings caused by sulfhydryl-containing drugs. Furthermore, ketone bodies increase first in blood than in urine, allowing earlier DKA diagnosis than dipstick urine tests. Most authors agree that normal ketonaemia is lower than $0.5 \mathrm{mmol} / \mathrm{L}$, hyperketonaemia is higher than $1 \mathrm{mmol} / \mathrm{L}$, and generally during ketoacidosis ketonaemia is higher than $3 \mathrm{mmol} / \mathrm{L}$. Nevertheless, during prolonged fasting ketonaemia may reach $6 \mathrm{mmol} / \mathrm{L}$ [25].

Demonstration that resolution of DKA depends upon resolution of ketosis has moved treatment goal from a glucocentric to ketocentric perspective. Umpierrez et al. found that DKA was resolved in all patients with $\beta$-hydroxybutyrate lower than $0.5 \mathrm{mmol} / \mathrm{L}$, but wasn't in any patient with $\beta$-hydroxybutyrate higher than $1.1 \mathrm{mmol} / \mathrm{L}$ [20]. This paradigm change was recently pointed out by the Joint British Diabetes Societies in the guidelines for The Management of Diabetic Ketoacidosis in Adults [26]. The clearance of $\beta$-hydroxybutyrate may be influenced by the route of insulin administration. Under the same dosing scheme of regular insulin, intravenous route was associated with faster glycaemia and $\beta$-hydroxybutyrate plus acetoacetate concentrations decrease and higher blood insulin levels than subcutaneous and intramuscular routes [27]. During the first hour of treatment, patients receiving intramuscular or subcutaneous insulin experienced an increase rather than a decrease on $\beta$-hydroxybutyrate plus acetoacetate concentrations. Furthermore, a $2 \mathrm{mmol} / \mathrm{L}$ decrease from pre-treatment ketone bodies concentration was seen after approximately 2, 4, and more than $4 \mathrm{~h}$ for intravenous, subcutaneous, and intramuscular routes, respectively. These differences reflect the slower achievement of therapeutic insulin blood concentration with subcutaneous and intramuscular routes. In fact, after $8 \mathrm{~h}$ of treatment no significant differences were observed in either glucose or $\beta$ hydroxybutyrate plus acetoacetate concentrations among the three routes. However, as it will be discussed later, when therapeutic concentrations of insulin are achieved with the new fast-acting analogues, similar clearance patterns of $\beta$ hydroxybutyrate and glucose may be observed with intravenous and subcutaneous routes. 
Complete initial evaluation. Check blood capillary glucose and serum/urine ketones to confirm hyperglycaemia and ketonaemia/ketonuria. Obtain blood for metabolic profile. Start IV fluids: $1.0 \mathrm{~L}$ of $0.9 \% \mathrm{NaCl}$ per hour $(15-20 \mathrm{~mL} / \mathrm{kg} / \mathrm{h})$
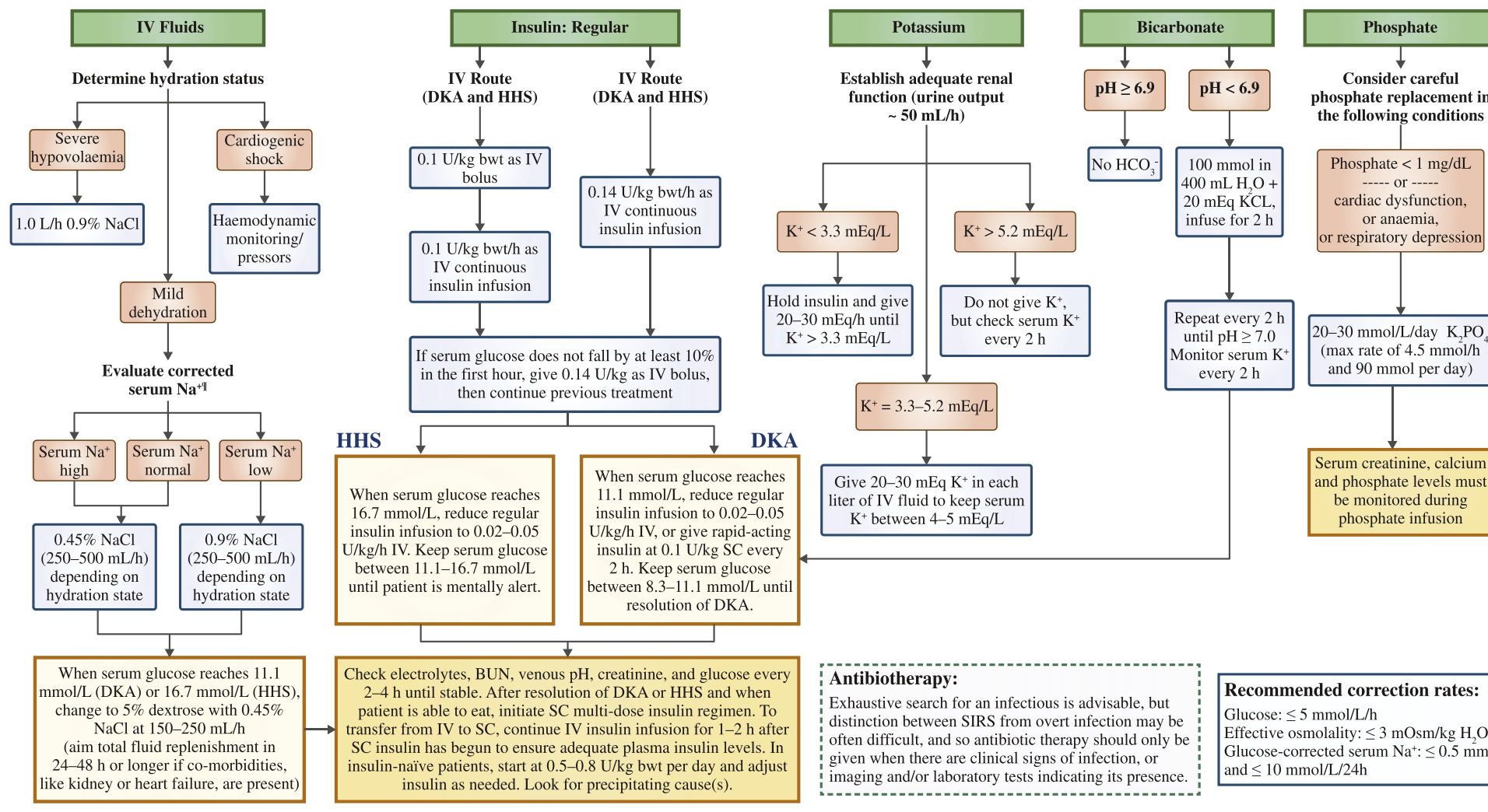
the following conditions
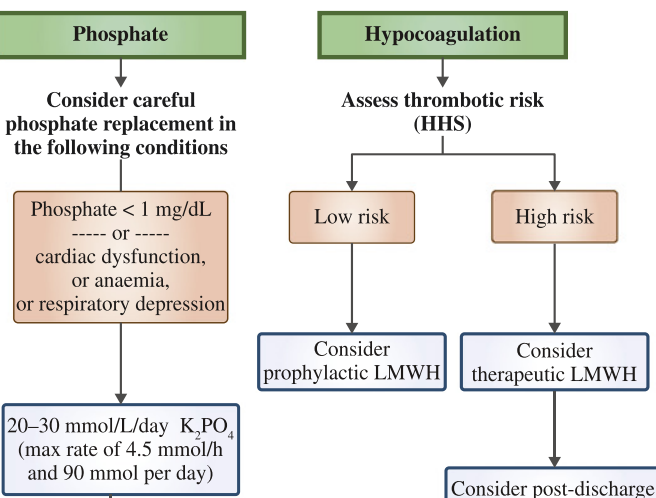

Consider
prophylactic LMWH

and 90 af 4.5 minol/

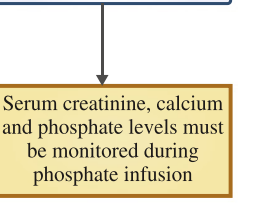

$\mathrm{K}^{+}=3.3-5.2 \mathrm{mEq} / \mathrm{L}$

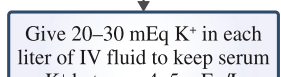

fluid to keep serum

Fig. 2 - Management of adult patients with DKA or HHS. " serum $\mathrm{Na}^{+}$should be corrected for hyperglycaemia (add 1.6-2.4 mmol/L per each $5.5 \mathrm{mmol} / \mathrm{L}$ of blood glucose decrease). Modified from references $[10,14,39]$. 
Surrogate markers of ketoacidosis, like $\mathrm{pH}$, bicarbonate, and anion gap are unspecific and influenced by several factors: degree of ventilatory compensation, other acid-base disturbances, and treatment [28]. For this reason they shouldn't be used to monitor insulin therapy or DKA resolution. Point-of-care (POC) capillary $\beta$ hydroxybutyrate blood tests have a reasonable agreement with laboratory serum ketone tests $(95 \%$ limits of agreement -0.9 to $1 \mathrm{mmol} / \mathrm{L}$ ) and a mean difference between tests of $-0.03 \mathrm{mmol} / \mathrm{L}$ [29]. Byrne et al. showed that POC tests give accurate results up to $6 \mathrm{mmol} / \mathrm{L}$ [29]. Another study showed that POC tests are reliable up to $3 \mathrm{mmol} / \mathrm{L}$ of $\beta$-hydroxybutyrate but for levels above $5 \mathrm{mmol} / \mathrm{L}$ accuracy is lower [30]. Nevertheless, capillary ketone POC tests have proven to accelerate DKA resolution 5-11 h faster than urine ketone dipstick tests [31,32].

Quantitative blood $\beta$-hydroxybutyrate tests should be preferred over urine ketone testing for diagnosing and monitoring DKA [24]. In fact, blood POC ketone tests may prevent DKA episodes, ease DKA management, and shorten intensive care length of stay when compared with urine dipstick tests [32,33].

A)
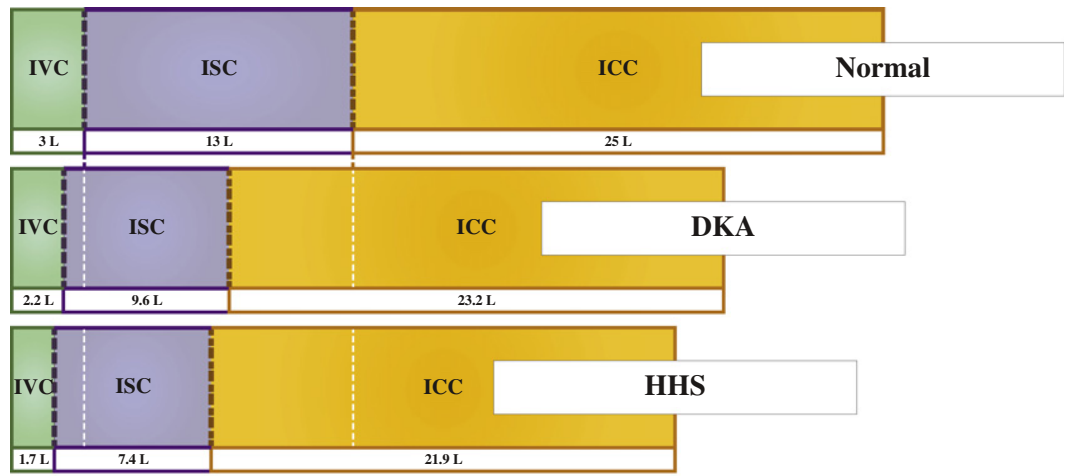

B)

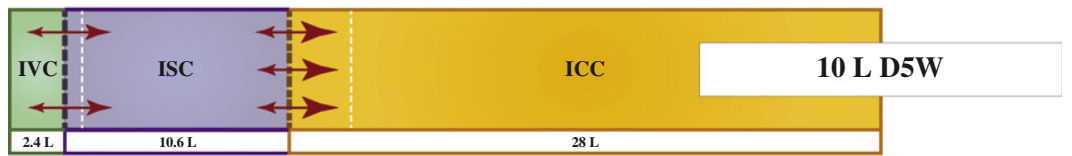

C)

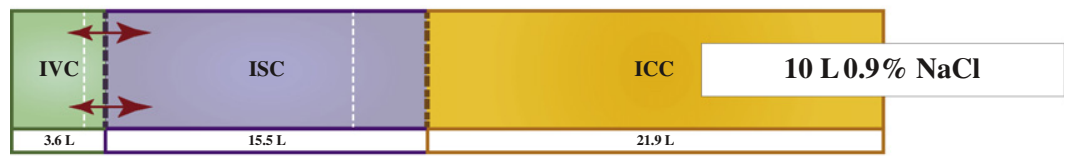

D)

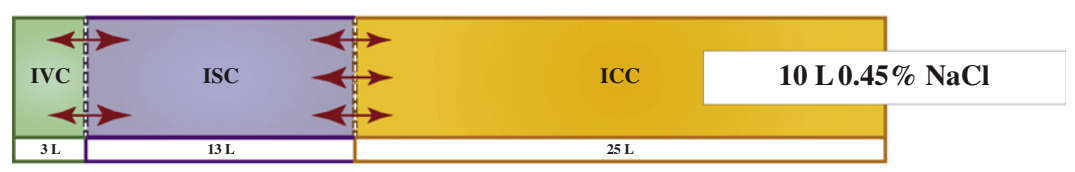

E)

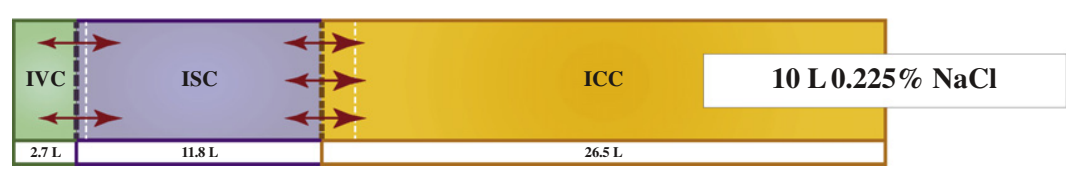

Fig. 3 - Water shifts in hyperglycaemic emergencies. Panel A) Total body water represents approximately $60 \%$ of total body mass. A male with a body weight of $70 \mathrm{~kg}$ will have about $42 \mathrm{~L}$ of total body water (25 L in the intracellular compartment (ICC), and $17 \mathrm{~L}$ extracellular, of which $13 \mathrm{~L}$ in interstitial compartment (ISC) and $3 \mathrm{~L}$ in the intravascular compartment (IVC), and $1 \mathrm{~L}$ in transcellular compartment). Patients with hyperglycaemic emergencies lose hypotonic fluids similar to "half normal" solution. So, for a water deficit of $6 \mathrm{~L}$ (DKA) it is expectable a decrease of $0.8 \mathrm{~L}, 3.4 \mathrm{~L}$, and $1.8 \mathrm{~L}$ of water in the IVC, ISC, and ICC, respectively. For a water deficit of $10 \mathrm{~L}$ (HHS) it is expectable a decrease of $1.3 \mathrm{~L}, 5.6 \mathrm{~L}$, and $3.1 \mathrm{~L}$ of water in the IVC, ISC, and ICC, respectively. The following panels represent the water shifts caused by different solutions in a patient with hyperglycaemic emergency and a total water deficit of $10 \mathrm{~L}$. Panel B) Correction of water deficit with 5\% glucose solution (D5W) results in suboptimal replenishment of IVC, and ISC, and excessive replenishment of ICC because water is distributed proportionally between the three compartments (IVC 0.7 L, ISC 3.2 L, and ICC 6.1 L) with D5W solutions. Panel C) $0.9 \% \mathrm{NaCl}$ solution is exclusively distributed in the extracellular compartment resulting in excessive replenishment of IVC and ISC (IVC $1.9 \mathrm{~L}$ and ISC $8.1 \mathrm{~L}$ ). Panel D) $0.45 \% \mathrm{NaCl}$ solution closely resembles the fluid lost by HHS and DKA patients (IVC 1.3 L, ISC 5.6 L, and ICC 3.1 L) and probably is the best option in patients with normal or high sodium concentration and without severe hypovolaemia. Panel E) $0.225 \% \mathrm{NaCl}$ will again result in suboptimal replenishment of IVC and ISC, and excessive ICC replenishment (IVC 1 L, ISC 4.4 L, and ICC 4.6 L). 


\section{Fluid Replacement}

\subsection{Effective Osmolality Calculation}

Water deficit in DKA ranges from 3 to $6 \mathrm{~L}$, and in HHS is even greater, ranging from 8 to $10 \mathrm{~L}$ [13]. Fluid therapy should be started immediately after the diagnosis of hyperglycaemic emergency is done and should aim restoration of depleted intravascular and interstitial volume, tissue perfusion, normal tonicity, and decrease of counter-regulatory hormones.

Serum osmolality is tightly regulated and averages $288 \pm$ $5 \mathrm{mOsm} / \mathrm{kg} \mathrm{H}_{2} \mathrm{O}$. It may be directly measured by osmometers or calculated recurring to equations that ponder different contributions of sodium, glucose, and urea [34]. More recently, equations were built with contributions of other osmolytes, like potassium, bicarbonate, magnesium, calcium, chloride, and lactate. Effective osmolality, or tonicity, corresponds to the portion of osmolality inducing transmembrane water movement. Urea and ethanol easily cross cell membrane and contribute to osmolality but not to effective osmolality. Osmolality correlates well with mental status. Stupor and coma typically occur when total and effective osmolalities are higher than 340 and $320 \mathrm{mOsm} / \mathrm{kg} \mathrm{H}_{2} \mathrm{O}$, respectively [10]. Indeed, if coma occurs with lower levels of osmolality it shall prompt active search for other causes of altered mental status. However, altered mental status may occur with effective osmolality less than $320 \mathrm{mOsm} / \mathrm{kg} \mathrm{H}_{2} \mathrm{O}$ in DKA, mainly reflecting the degree of acidosis [35]. The mechanism of brain oedema in DKA is controversial. Steep decreases in effective osmolality, contributing to cellular oedema, and the systemic inflammatory response of DKA, contributing to vasogenic oedema, may be involved [36,37]. Other potential contributors to brain oedema are hypoperfusion before treatment, post-treatment reperfusion, insulin, and sodium bicarbonate therapy [38]. Similar processes should develop in adults, and cerebral oedema has been associated with fast decreases in effective osmolality. Effective osmolality has advantages over total osmolality and should guide fluid replacement, because it is not affected by ineffective osmolytes and so it's a better indicator of treatment response. Additionally, it directly reflects the opposite trends of sodium and glucose concentrations, two major effects of dehydration and insulinopaenia, respectively. To prevent cerebral oedema, effective osmolality shouldn't decrease more than $3 \mathrm{mOsm} / \mathrm{kg} \mathrm{H}_{2} \mathrm{O}$ per hour [39].

\subsection{Type and Tonicity of Fluid Replacement}

There has been great debate about the type and tonicity of fluid replacement. Colloid solutions have no superiority over crystalloids. On the contrary, they were associated with increased death and acute kidney injury [40,41]. Zarychanski et al. reported increased risk of mortality of $9 \%$, acute kidney injury of $27 \%$, and renal replacement therapy of $32 \%$ when administering hydroxyethyl starch to critically ill patients requiring volume resuscitation [42]. A Cochrane review reported similar results and recommended against the use of colloids (as opposed to crystalloids) to fluid resuscitation in critically ill patients [43].

DKA or HHS patients lose hypotonic fluids similar to "half normal" solution, half from intracellular compartment and half from extracellular compartment, rendering total fluid loss replacement with $0.45 \% \mathrm{NaCl}$ solution a reasonable approach (Fig. 3) [44]. Nevertheless, rapid changes of effective osmolality should be avoided due to the risk of cerebral oedema. Long-term retention of solutes and idiogenic osmoles by the brain generally overrides the osmotic gradient with plasma. However, DKA patients are particularly susceptible to brain oedema due to high intracellular osmolality, that may quickly precipitate oedema if rapid decreases in plasmatic osmolality occur without enough time for neuron adaptation. Hoorn et al. showed, in children with DKA, that effective osmolality decreases during the first $4 \mathrm{~h}$ of treatment were significantly more pronounced in patients with brain oedema than in patients without brain oedema, with or

Table 2 - Composition of common intravenous solutions.

\begin{tabular}{|c|c|c|c|c|c|c|c|c|c|c|c|}
\hline \multirow{2}{*}{ Fluid } & $\mathrm{Na}^{+}$ & $\mathrm{Cl}^{-}$ & $\mathrm{K}^{+}$ & $\mathrm{Ca}^{*}$ & $\mathrm{Mg}^{*}$ & $\mathrm{HCO}_{3}^{-}$ & Lactate & Glucose ๆ & Calories & Osmolarity & \multirow{2}{*}{$\mathrm{pH}$} \\
\hline & $(\mathrm{mmol} / \mathrm{L})$ & $(\mathrm{mmol} / \mathrm{L})$ & $(\mathrm{mmol} / \mathrm{L})$ & $(\mathrm{mmol} / \mathrm{L})$ & (mmol/L) & $(\mathrm{mmol} / \mathrm{L})$ & $(\mathrm{mmol} / \mathrm{L})$ & $(\mathrm{mmol} / \mathrm{L})$ & (Kcal/L) & $(\mathrm{mOsm} / \mathrm{L})$ & \\
\hline Plasma & $135-144$ & $95-105$ & $3.5-5.3$ & $2.2-2.6$ & $0.8-1.2$ & $23-30$ & $1.0-2.0$ & $3.9-6.1$ & - & 308 & $7.35-7.45$ \\
\hline $0.9 \% \mathrm{NaCl}$ & 154 & 154 & - & - & - & - & - & - & - & 308 & $4.5-7.0$ \\
\hline $0.45 \% \mathrm{NaCl}$ & 77 & 77 & - & - & - & - & - & - & - & 154 & $4.5-7.0$ \\
\hline D5 $0.225 \% \mathrm{NaCl}$ & 38 & 38 & - & - & - & - & - & 278 & 170 & 329 & $3.5-6.5$ \\
\hline D5 $0.45 \% \mathrm{NaCl}$ & 77 & 77 & - & - & - & - & - & 278 & 170 & 406 & $3.5-6.5$ \\
\hline D5 $0.9 \% \mathrm{NaCl}$ & 154 & 154 & - & - & - & - & - & 278 & 170 & 560 & $3.5-6.5$ \\
\hline D5 Water & - & - & - & - & - & - & - & 278 & 170 & 252 & $3.5-6.5$ \\
\hline Hartmann's Solution & 131 & 111 & 5 & 2 & - & - & 29 & - & - & 278 & $5.0-7.0$ \\
\hline Ringer's Lactate & 130 & 109 & 4 & 1.35 & - & - & 28 & - & - & 273 & $6.0-7.5$ \\
\hline Ringer's Acetate & 130 & 112 & 5 & 1 & 1 & - & $\S$ & - & - & 276 & $6.0-8.0$ \\
\hline $3 \% \mathrm{NaCl}$ & 513 & 513 & - & - & - & - & - & - & - & 1026 & $4.5-7.0$ \\
\hline Bicarbonate $8.4 \%$ & 1000 & - & - & - & - & 1000 & - & - & - & 2000 & $7.5-8.5$ \\
\hline
\end{tabular}

" Mean normal blood glucose level in humans. D5, 5\% D-glucose monohydrate solution. To convert millimoles per litre to milligrams per decilitre, multiply by 18 .

* Total calcium and magnesium plasmatic levels.

$\S 27 \mathrm{mmol} / \mathrm{L}$ of acetate. 
without hypernatraemia [36]. Herein, patients with cerebral oedema received more fluids than the others $(69 \pm 9 \mathrm{~mL} / \mathrm{kg}$ us $27 \pm 3 \mathrm{~mL} / \mathrm{kg}$ us $35 \pm 2 \mathrm{~mL} / \mathrm{kg}$, respectively). This intravascular volume over-expansion caused by isotonic saline solutions can trigger a complex process of "desalination". Durward et al. observed an effective osmolality and glucose-corrected sodium pattern closely resembling desalination in patients with late-onset brain oedema [45]. Vasopressin, possibly through renin-angiotensin-aldosterone system, increased natriuretic peptide, or increased glomerular filtration may be implicated. The net effect is a decrease in total sodium content, or at least a lower than predicted sodium increase for the level of glycaemia, which may confer a higher risk of cerebral oedema. Moreover, patients with plasmatic sodium lower than $135 \mathrm{mmol} / \mathrm{L}$ may be more prone to develop cerebral oedema, and by opposition patients with plasmatic sodium higher than $145 \mathrm{mmol} / \mathrm{L}$ may tolerate better the effect of glucose decrease on effective osmolality [46].

The best composition of isotonic solution remains controversial. Despite the wide clinical experience with normal saline solutions, there is concern with supra-physiological osmolality, and sodium and chloride concentrations (Table 2). In 1933, Kydd documented hyperchloraemic acidosis after administration of saline solution [47]. In fact hyperchloraemic acidosis is a predictable consequence of rapid infusion of large amount of saline solution attributed to the expansion of extracellular volume and consequent bicarbonate dilution, with reduction of buffering capacity, hence the term of dilutional acidosis.

Another concern regarding normal saline solutions is the higher than plasma concentration of sodium, that can delay the correction of natraemia and osmolality. Balanced solutions, like Hartman and Ringer's lactate, resemble more closely the composition of human plasma and are unlikely to worsen hypernatraemia or hyperchloraemic acidosis, though its potassium and lactate content generate worries. DKA and HHS patients may have hyperkalaemia at presentation, even though total body potassium is depleted. In this situation it is prudent to halt potassium supplementation. Lactate is metabolized, mostly in the liver, by gluconeogenesis (70\%) and consumption of $\mathrm{H}^{+}$, and through oxidation $(30 \%)$ generating $\mathrm{CO}_{2}$ and $\mathrm{H}_{2} \mathrm{O}$, consumption of $\mathrm{H}^{+}$, and ultimately increasing bicarbonate concentration. The expectable net effect would be worsening of hyperglycaemia and some improvement on acidosis. A recent randomized controlled trial (RCT) conducted by Zyhl et al. failed to demonstrate benefit of Ringer's lactate over normal saline in DKA resolution time [48]. Furthermore, the time to reach a blood glucose level of $14 \mathrm{mmol} / \mathrm{L}$ was significantly longer in the group treated with Ringer's lactate solution than in the group with normal saline.

\subsection{Rate of Fluid Perfusion}

Current guidelines recommend that total fluid loss should be replaced during the first $24-48 \mathrm{~h}[14,26,49,50]$. Special considerations are given to patients with kidney or heart failure. Normalization of electrolytes and osmolality may take up to $72 \mathrm{~h}$, or even more if metabolic disturbance is severe and/or if important co-morbidities are present. There are no RCT assessing the rate of fluid replacement. Until prospective data is available, some general rules may be helpful to safely guide the rate of fluid reposition. First, osmolality should not decrease more than $3 \mathrm{mOsm} / \mathrm{kg} \mathrm{H}_{2} \mathrm{O}$ per hour in order to prevent osmotic shifts of water to intracellular compartment [39]. Initially, frequent (hourly) effective osmolality assessment is advised to adjust the rate of fluid replacement and to safely ensure a positive fluid balance [50]. Second, using lowdose insulin infusion protocols a decrease in plasma glucose concentration at a rate of $2.8-4.2 \mathrm{mmol} / \mathrm{L}$ per hour is expectable, and if such decrease (or a $10 \%$ decrease in glycaemia) does not occur in the first hour, a $0.14 \mathrm{U} / \mathrm{kg}$ intravenous bolus should be given. However, caution is recommended because it has been advocated that glucose shouldn't decrease more than $5 \mathrm{mmol} / \mathrm{L}$ per hour [14,50]. Furthermore, fluid administration alone may result in significant improvement of hyperglycaemia, osmolality, and acidaemia due to a decline in counter-regulatory hormone levels, reduced peripheral insulin resistance, and renal perfusion, which leads to increased glucose excretion. The net effect is a decrease of glycaemia of $1.4-2.8 \mathrm{mmol} / \mathrm{L}$ per hour with hydration alone [51]. Third, fall of plasma sodium should not exceed $10 \mathrm{mmol} / \mathrm{L} / 24 \mathrm{~h}$ and $0.5 \mathrm{mmol} / \mathrm{L}$ per hour in order to prevent cerebral oedema and convulsions [52]. One should expect an increase in sodium levels of 1.6-2.4 $\mathrm{mmol} / \mathrm{L}$ per each $5.5 \mathrm{mmol} / \mathrm{L}$ of blood glucose decrease [53,54]. Indeed, in the setting of HHS, rising sodium levels should only be a concern if osmolality is not declining simultaneously, and it is not necessarily an indication to hypotonic fluids administration. However, if the sodium rise is much greater than $2.4 \mathrm{mmol} / \mathrm{L}$ for each $5.5 \mathrm{mmol} / \mathrm{L}$ fall in blood glucose this suggests insufficient fluid replacement.

\subsection{Management during the three Phases of Fluid Replacement}

Three phases of fluid replacement may be found: first, when the patient is severely hypovolaemic; second, when the patient is euvolaemic or mildly hypovolaemic but glycaemia is higher than $11.1-16.6 \mathrm{mmol} / \mathrm{L}$; third, when glycaemia is below 11.1-16.6 mmol/L. Fluid losses cause greater impact in the intravascular and interstitial compartments than in the intracellular compartment. Baring this in mind, the first fluid solution should be preferentially distributed between extracellular compartments, particularly to restore intravascular volume and end-organ perfusion. Normal saline is restricted to extracellular compartment and $1 \mathrm{~L}$ of solution contributes with $180 \mathrm{~mL}$ to the intravascular compartment. Kitabchi et al. advocate that, in the absence of heart or kidney failure, normal saline solution should be infused at a rate of 15-20 mL/kg per hour or 1-1.5 L during the first hour [14]. After urgent intravascular expansion is accomplished, complete replenishment of all compartments should be sought in the first 24-48 h. During the second phase, the type and rate of fluid replacement depends on the state of hydration, serum electrolyte levels, and urinary output. If the corrected serum sodium is normal or elevated, in general, it's appropriate to infuse $0.45 \% \mathrm{NaCl}$ at $250-500 \mathrm{~mL}$ per hour; $0.9 \% \mathrm{NaCl}$ at a similar rate is preferable if corrected serum sodium is low. 
Anyway, if a hypernatraemic patient has haemodynamic instability, $0.9 \% \mathrm{NaCl}$ should be preferred over $0.45 \% \mathrm{NaCl}$ solution. The relative contributions to intravascular compartment of $1 \mathrm{~L}$ of each solution are $180 \mathrm{~mL}$ and $70 \mathrm{~mL}$, respectively, and so effective replenishment would take much longer with the latter solution. The last phase occurs when the patient with HHS or DKA reaches a blood glucose of $16.6 \mathrm{mmol} / \mathrm{L}$ or $11.1 \mathrm{mmol} / \mathrm{L}$, respectively. At this time, 5\% dextrose should be initiated to allow continued insulin administration until insulinopaenia is corrected.

Taken together, these data show that initial treatment with $0.9 \% \mathrm{NaCl}$ solution supplemented with potassium as needed is both rational and safe, because: 1) the majority of electrolyte losses are sodium, chloride, and potassium; 2) effectively replenishes intravascular compartment and re-establishes tissue perfusion; 3) it is a safe option until the risk of brain oedema is assessed and laboratorial results are available; 4) normal saline solutions are already more hypotonic than the plasma of HHS patients $(286 \mathrm{mOsm} / \mathrm{kg}$ us $320 \mathrm{mOsm} / \mathrm{kg}$, respectively).

\section{Insulin Therapy}

\subsection{Priming Dose of Insulin}

Fluid replacement therapy is able to suppress most of pathophysiologic effects of insulinopaenia. Indeed, insulin therapy should not be started until electrolyte results are available to prevent potentially lethal hypokalaemia.

In the early years of insulin, hyperglycaemic crisis were treated with low-dose regimens due to the scarce availability of insulin. Even though low-dose protocols were effective, they were replaced, between 1950 and 1970, by high-dose regimens of 25-100 U/h given by intravenous, intramuscular, or subcutaneous route. In 1973, Alberti et al. proposed a new regimen for DKA treatment using low-dose intramuscular insulin [55]. Herein, administration of an initial average bolus of $16 \mathrm{U}$ followed by $5-10 \mathrm{U} / \mathrm{h}$ of intramuscular regular insulin was effective in correcting hyperglycaemia and metabolic acidosis without the deleterious effect on potassium levels of previous high-dose regimens [55]. Subsequently Kitabchi et al. undertook a series of prospective randomized trials that definitely demonstrated the efficacy of low-dose protocols in the treatment of DKA [56,57]. Patients treated with high-dose insulin regimens (total dose of $263 \pm 45 \mathrm{U}$ ) and low-dose regimens (total dose of $46 \pm 5 \mathrm{U}$ ) had similar outcomes, but there was a significant reduction in hypokalaemia and no event of hypoglycaemia occurred in the low-dose group. Another study demonstrated the advantages of intravenous route. Fisher et al. randomly assigned 45 patients to receive low-dose insulin intravenously, subcutaneously, or intramuscularly, with an initial bolus of $0.33 \mathrm{U} / \mathrm{kg}$, followed by $7 \mathrm{U} / \mathrm{h}$ of regular insulin until plasma blood glucose reached $13.9 \mathrm{mmol} / \mathrm{L}$ [27]. Intravenous route was associated with faster blood glucose and ketone bodies decrease. Furthermore, 13\%, 20\%, and 40\% of patients receiving insulin by intravenous, subcutaneous, and intramuscular routes, respectively, failed to achieve a $10 \%$ decrease on plasma glucose in the first hour of treatment and required additional priming bolus of insulin.
Insulin-priming dose was therefore advocated [10]. However, loading dose of insulin may result in hypokalaemia and brain oedema, particularly in children. Kitabchi et al. assessed this issue in a RCT [58]. Three insulin regimens were analyzed: 1) load group: using a priming dose of $0.07 \mathrm{U} / \mathrm{kg}$ of regular insulin followed by a dose of $0.07 \mathrm{U} / \mathrm{kg}$ per hour intravenously; 2) no load group: using an infusion of regular insulin of $0.07 \mathrm{U} /$ kg per hour without a priming dose, and 3) twice no load group: using an infusion of regular insulin of $0.14 \mathrm{U} / \mathrm{kg}$ per hour without a priming dose. Load group reached an insulin peak sooner and taller ( $460 \mu \mathrm{U} / \mathrm{mL}$ at five minutes) than no load group ( $60 \mu \mathrm{U} / \mathrm{mL}$ at $60-120 \mathrm{~min}$ ) and twice no load group (200 $\mu \mathrm{U} / \mathrm{mL}$ at $45 \mathrm{~min})$. However, insulin plateau was higher in the latter group than in the formers, DKA resolution (glucose $\leq 13.9 \mathrm{mmol} / \mathrm{L}, \mathrm{pH} \leq 7.3$, and bicarbonate $\leq 15 \mathrm{mEq} / \mathrm{L}$ ) did not differ significantly among the three groups. Based on this study, if an adequate insulin perfusion is assured, there is no need for loading dose.

\subsection{Variable or Fixed-Rate Intravenous Insulin Perfusion}

Widely used variable rate or 'sliding scale' insulin infusions (VRIII) have been replaced by weight-based fixed rate intravenous insulin infusion (FRIII) $[14,26,50]$. VRIII therapy may result in relatively normal blood glucose but blood ketones may remain high, due to inappropriate low levels of administered insulin. Wiggam et al. showed that keeping patients at a fixed rate of insulin ( $5 \mathrm{U} / \mathrm{h})$ until ketonaemia has been resolved ( $\beta$-hydroxybutyrate $<0.5 \mathrm{mmol} / \mathrm{L}$ ), as opposed to a regimen where insulin rate was changed from $5 \mathrm{U} / \mathrm{h}$ to $1.3 \mathrm{U} / \mathrm{h}$ once glycaemia reached $10 \mathrm{mmol} / \mathrm{L}$, allowed a significantly faster resolution of ketosis $(10.8 \pm 1.1 \mathrm{~h}$ us $25.2 \pm 3.7$ h) [59].

Intravenous insulin should reach a plasmatic concentration high enough to counteract hepatic glucose production, lipolysis, and ketosis. Suppression of hepatic glucose production is particularly important because insulin lowers serum glucose primarily by inhibiting gluconeogenesis rather than enhancing peripheral utilization [60]. Wagner et al. treated 114 DKA patients without any casualty using a very-low-dose of $1 \mathrm{U} / \mathrm{h}$ of insulin following an initial bolus of $6.2 \mathrm{U}$ [61]. However, treatment was driven to achieve a reduction in blood glucose level of $2.8 \mathrm{mmol} / \mathrm{L}$ per hour and no data was reported regarding ketosis resolution. A paediatric study using a lowdose insulin regimen of $0.1 \mathrm{U} / \mathrm{kg}$ per hour intravenously resulted in a plasma insulin of $50-60 \mu \mathrm{U} / \mathrm{mL}$. Such levels of plasma insulin are not enough to suppress hepatic glucose production and stimulate peripheral glucose uptake, which require $80-100 \mu \mathrm{U} / \mathrm{mL}$ of total insulin for complete suppression and $70-80 \mu \mathrm{U} / \mathrm{mL}$ for half-maximal insulin stimulatory effect on peripheral glucose uptake $[60,62]$. Nevertheless, it may be enough to suppress lipolysis and ketogenesis. Regular insulin infusion of $0.14 \mathrm{U} / \mathrm{kg}$ per hour, without a priming dose, resulted in plateau levels of insulin higher than $100 \mu \mathrm{U} / \mathrm{mL}$, which are able to completely suppress hepatic glucose output, lipolysis, ketogenesis, and, to a lesser extent, increase peripheral glucose uptake [58]. The increasingly high prevalence of obesity adds rationale to the principle of adjusting insulin rate to body weight. When ketone concentration is not falling fast enough and/or bicarbonate level is not rising fast enough, other insulin 
resistant states, like infection, should alert the clinician to review the insulin rate.

\subsection{Continuation of Basal Insulin with Intravenous Perfusion}

Transition from intravenous insulin infusion to subcutaneous insulin frequently results in rebound hyperglycaemia, particularly if there are high insulin requirements.

Hsia et al. undertook a RCT comparing 31 patients treated with regular insulin infusion and 30 patients treated with regular insulin infusion plus $0.25 \mathrm{U} / \mathrm{kg}$ of daily glargine [63]. The length of insulin infusion was lower in glargine group (35 h us $42 \mathrm{~h}$ ), though not statistically significant. Total insulin infusion within the $24 \mathrm{~h}$ before discontinuation was similar in both groups. At least one episode of rebound hyperglycaemia occurred in $94 \%$ of control group subjects and only in $33 \%$ of glargine group during the $12 \mathrm{~h}$ following insulin infusion discontinuation. Shankar et al. retrospectively assessed the usefulness of insulin glargine in the first $6 \mathrm{~h}$ of management of DKA in addition to the standard treatment [64]. Glargine treated patients had shorter insulin infusion time $(14.8 \pm 6.0 \mathrm{~h}$ us $24.4 \pm$ $9.0 \mathrm{~h})$, lower total infused insulin dose $(43.0 \pm 31.6 \mathrm{U}$ us $89.4 \pm$ $68.8 \mathrm{U})$, and shorter total hospital stay ( $3.2 \pm 1.0$ days us $3.72 \pm$ 1.06 days). Furthermore, insulin glargine co-administration with regular insulin infusion may be associated with faster resolution of acidosis without any adverse effects $(12.4 \pm 2.9 \mathrm{~h}$ vs $17.1 \pm 6.2 \mathrm{~h}$ ). Taken together, these results suggest that simultaneous administration of basal insulin and infusion of regular insulin decrease rebound hyperglycaemia, accelerate ketoacidosis resolution, and may decrease insulin infusion time, dose, and total hospital stay.

\subsection{Short-Acting Insulin Analogues}

After introduction of short-acting analogues other therapeutic regimens for hyperglycaemic emergencies emerged.

Umpierrez et al. randomly assigned patients to be treated with regular or glulisine insulin infusion until resolution of DKA [65]. Glulisine and regular insulin groups had similar duration of insulin infusion, time for DKA resolution, total amount of insulin until DKA resolution, and length of stay. However, regular insulin infusion is more cost-effective and should be preferred over rapid-acting insulin analogues during the intravenous insulin treatment.

Taking in consideration the attractive pharmacokinetic characteristics of insulin analogues, Umpierrez et al. conducted a RCT, in mild to moderate DKA patients, comparing the efficacy and safety of subcutaneous insulin lispro administered hourly with intravenous infusion of low-dose regular insulin [66]. Subcutaneous lispro and regular insulin infusion groups had similar time required for DKA and hyperglycaemia resolution, total amount of insulin, and length of stay. However, hospitalization associated costs were reduced by $39 \%$ in the subcutaneous insulin group ( $\$ 8801 \pm \$ 5549$ us $\$ 14,429 \pm \$ 5243$ ) mainly due to treatment management in general medicine wards or intermediate care units and not in intensive care units.

These findings were reproduced by other groups and globally suggest that subcutaneous rapid-acting insulin analogues, administered each $1-2 \mathrm{~h}$, are effective and safe alternatives to insulin infusion treatment in patients with mild to moderate DKA $[67,68]$. Longer administration intervals may not be enough to suppress hepatic glucose production and ketosis resolution. These studies enrolled a total of 201 patients with mild to moderate DKA and more robust data are needed to confirm these findings. Furthermore, subcutaneous administration of insulin each 1 or $2 \mathrm{~h}$ may not be feasible in some general medicine wards, impeding the great benefit of this approach in precluding intensive care unit admission.

\section{Electrolyte Management}

Sodium concentration is usually low due to osmotic shift of water from intracellular to extracellular compartment in the setting of hyperglycaemia and hyperosmolality. Water replenishment and sodium correction should be guided by the previous recommendations.

Total potassium content is decreased, but serum potassium concentration may be normal/elevated due to extracellular shift of potassium caused by insulin deficiency, hypertonicity, and acidaemia [69]. Patients with low normal/ low serum potassium concentration on admission or on diuretics have severe total-body potassium deficiency and require vigorous replacement and close monitoring to avoid cardiac arrhythmias. HHS patients have more severe potassium depletion than DKA patients and, in the absence of acidosis, intracellular shift of potassium is accelerated in response to insulin. In this case, the average requirement is 20-30 $\mathrm{mEq} / \mathrm{h}$.

Serum phosphate and erythrocyte diphosphoglycerate content are depleted, thus shifting the oxygen dissociation curve to the left and limiting tissue oxygen delivery [70]. However, at admission serum phosphate concentrations may be normal or elevated, because, like potassium, phosphate shifts from the intracellular to the extracellular compartment in the setting of hyperglycaemia, hyperosmolality, insulin deficiency, and hypercatabolic state [71,72]. Osmotic diuresis worsens urinary phosphate losses. During insulin treatment, shifts from extracellular to the intracellular compartment cause mild to moderate hypophosphataemia [10]. RCT failed to demonstrate clinical benefit of routinely replacing phosphate and severe hypocalcaemia may complicate the treatment [71]. Patients with phosphate concentrations lower than $1.0 \mathrm{mg} / \mathrm{dL}$ or patients with moderate hypophosphataemia and respiratory failure, anaemia, or cardiac dysfunction should receive intravenous phosphate replacement [10]. There are no studies regarding the treatment of hypophosphataemia in HHS patients; however, they may have more severe phosphate depletion than DKA patients and close monitoring is advised.

Replacement of bicarbonate in DKA is controversial. Some defend bicarbonate replacement fearing the effects of acidosis on cardiac haemodynamics, while others preclude its utilization fearing cerebrospinal acidosis and subsequent right shift of oxyhaemoglobin [56]. Insulin treatment suppresses ketogenesis and promotes ketoanion metabolism, consuming protons and generating bicarbonate, which contributes to correction of acidosis. Morris et al. conducted a RCT in 21 moderate to severe DKA patients and found no improvement 
in the recovery outcome variables [73]. Nevertheless, bicarbonate therapy may be associated with hypokalaemia, central nervous system hypoxia, and oedema. Current guidelines advocate that sodium bicarbonate should be given when $\mathrm{pH}$ is lower than 6.90. However, patients with hyperchloraemic metabolic acidosis as the main driver to acidaemia or patients with low capacity of ketoacid removal should receive bicarbonate at a rate similar to hepatic ketoacid production $(\sim 60 \mathrm{mmol} / \mathrm{h})[74]$.

\section{Hypocoagulation}

Patients with hyperglycaemic crisis have increased risk of both arterial and venous thrombosis, higher in HHS than DKA, and similar to patients with acute renal failure, sepsis, or connective tissue diseases [75]. The incidence of venous thrombosis in HHS may be related to hyperosmolarity, hyperglycaemia, hypernatraemia, and elevated levels of antidiuretic hormone [76]. This high risk, with impact on prognosis, supports the prophylactic use of lowmolecular-weight heparin (LMWH) for the full duration of admission unless contraindicated [50]. Nevertheless, the issue of prophylactic or full dose of LMWH in the setting of hyperglycaemic emergencies remains controversial. Unfortunately, there are no randomized trials comparing risk-benefit profile of prophylactic and full dose of LMWH. Case reports of thrombotic fatalities under prophylactic dose of LMWH may support the use of full LMWH dose in those with HHS and low hemorrhage risk [77]. Furthermore, Keenan et al. demonstrated that thrombotic risk is increased for three months after discharge, with one third of venous thromboembolism events occurring in that period [75]. These data support that extended prophylaxis after admission should be offered to high-risk patients.

\section{Conclusion}

Hyperglycaemic emergencies remain a serious complication of diabetes. Despite the management improvements seen in the last decades, as many as $5-20 \%$ of patients die from HHS. Additionally, as shown by Gibb et al. recurrent DKA is associated with increased risk of premature death, particularly among young, socially disadvantaged adults with high HbA1c levels [8]. Therefore, prevention of recurrent DKA is crucial for these patients. An integrated approach, including medical, psychological, and social care, as well as structured education programmes, should be provided for people with poorly controlled diabetes and/or at risk for DKA/HHS. Infection and medical noncompliance are the two most common causes of DKA and HHS. Patient education and permanent contact with diabetes healthcare team should be offered. Patients should be educated on how to manage their diabetes, particularly on "sick-days", that includes monitoring blood glucose more often, testing for ketosis, preventing dehydration, or administering supplemental rapid-acting insulin doses. Elderly, specifically those with limited mobility and those without previous knowledge of diabetes, are at high risk of HHS. In this regard, caregivers and relatives should be educated to recognize signs and symptoms of hyperglycaemia and dehydration.

Mainstays of treatment are insulin, electrolytes, and fluid replenishment. There is great need of clinical trials addressing the controversial areas of hyperglycaemic emergencies. Most evidence comes from trials undertaken by just a few groups around the world. The lack of studies may become problematic if mortality associated with hyperglycaemic emergencies (particularly HHS) doesn't decrease as a result of prevention. The increasing prevalence of diabetes predicts a proportionally growing number of hyperglycaemic emergencies events, which further supports the need of trials to optimize the management and decrease the morbi-mortality of hyperglycaemic emergencies.

\section{Conflict of Interest Statement}

We declare no competing interests.

\section{REFEREN C ES}

[1] von Stosch AW. Versuch einer pathologie und therapie des diabetes mellitus. Berlin: Duncker; 1828.

[2] Prout W. On the nature and treatment of stomach and renal diseases. London: John Churchill; 1843.

[3] Kussmaul A. Zur Lehre vom diabetes mellitus. Über eine eigenthümliche todesart bei diabetischen, über acetonämie, glycerin-behandlung des diabetes und einspritzungen von diastase in's blut bei dieser krankheit. Dtsch Arch Klin Med 1874;14:1-46.

[4] Dreschfeld J. The Bradshawe lecture on diabetic coma. Br Med J 1886;2:358-63.

[5] Centers for Disease Control and Prevention. Number of deaths for hyperglycemic crises as underlying cause, United States, 1980-2009; 2012. http://www.cdc.gov/diabetes/statistics/mortalitydka/fNumberOfDKA.htm [accessed 27.08.2016].

[6] Lin SF, Lin JD, Huang YY. Diabetic ketoacidosis: comparisons of patient characteristics, clinical presentations and outcomes today and 20 years ago. Chang Gung Med J 2005;28:24-30.

[7] Henriksen OM, Roder ME, Prahl JB, Svendsen OL. Diabetic ketoacidosis in Denmark incidence and mortality estimated from public health registries. Diabetes Res Clin Pract 2007;76:51-6.

[8] Gibb FW, Teoh WL, Graham J, Lockman KA. Risk of death following admission to a UK hospital with diabetic ketoacidosis. Diabetologia 2016;59:2082-7.

[9] Fritsch M, Schober E, Rami-Merhar B, Hofer S, FrohlichReiterer E, Waldhoer T, et al. Diabetic ketoacidosis at diagnosis in Austrian children: a population-based analysis, 1989-2011. J Pediatr 2013;163:1484-8 [e1].

[10] Kitabchi AE, Umpierrez GE, Murphy MB, Barrett EJ, Kreisberg RA, Malone JI, et al. Management of hyperglycemic crises in patients with diabetes. Diabetes Care 2001;24:131-53.

[11] Wachtel TJ, Tetu-Mouradjian LM, Goldman DL, Ellis SE, O'Sullivan PS. Hyperosmolarity and acidosis in diabetes mellitus: a three-year experience in Rhode Island. J Gen Intern Med 1991;6:495-502.

[12] Fadini GP, de Kreutzenberg SV, Rigato M, Brocco S, Marchesan $\mathrm{M}$, Tiengo A, et al. Characteristics and outcomes of the 
hyperglycemic hyperosmolar non-ketotic syndrome in a cohort of 51 consecutive cases at a single center. Diabetes Res Clin Pract 2011;94:172-9.

[13] Steenkamp DW, Alexanian SM, McDonnell ME. Adult hyperglycemic crisis: a review and perspective. Curr Diab Rep 2013;13:130-7.

[14] Kitabchi AE, Umpierrez GE, Miles JM, Fisher JN. Hyperglycemic crises in adult patients with diabetes. Diabetes Care 2009;32: 1335-43.

[15] Brandenburg MA, Dire DJ. Comparison of arterial and venous blood gas values in the initial emergency department evaluation of patients with diabetic ketoacidosis. Ann Emerg Med 1998;31:459-65.

[16] Gokel Y, Paydas S, Koseoglu Z, Alparslan N, Seydaoglu G. Comparison of blood gas and acid-base measurements in arterial and venous blood samples in patients with uremic acidosis and diabetic ketoacidosis in the emergency room. Am J Nephrol 2000;20:319-23.

[17] Ma OJ, Rush MD, Godfrey MM, Gaddis G. Arterial blood gas results rarely influence emergency physician management of patients with suspected diabetic ketoacidosis. Acad Emerg Med 2003;10:836-41.

[18] Fu P, Douros G, Kelly AM. Does potassium concentration measured on blood gas analysis agree with serum potassium in patients with diabetic ketoacidosis? Emerg Med Australas 2004; 16:280-3.

[19] Herrington WG, Nye HJ, Hammersley MS, Watkinson PJ. Are arterial and venous samples clinically equivalent for the estimation of $\mathrm{pH}$, serum bicarbonate and potassium concentration in critically ill patients? Diabet Med 2012;29:32-5.

[20] Umpierrez GE, Watts NB, Phillips LS. Clinical utility of betahydroxybutyrate determined by reflectance meter in the management of diabetic ketoacidosis. Diabetes Care 1995;18: 137-8.

[21] Csako G. False-positive results for ketone with the drug mesna and other free-sulfhydryl compounds. Clin Chem 1987;33:289-92.

[22] Montelongo A, Lasuncion MA, Pallardo LF, Herrera E. Longitudinal study of plasma lipoproteins and hormones during pregnancy in normal and diabetic women. Diabetes 1992;41: 1651-9.

[23] Pocellinko R, Solomon HM, Gaut ZN. Doped dipsticks. N Engl J Med 1969;281:1075.

[24] Goldstein DE, Little RR, Lorenz RA, Malone JI, Nathan D, Peterson CM, et al. Tests of glycemia in diabetes. Diabetes Care 2004;27:1761-73.

[25] Owen OE, Felig P, Morgan AP, Wahren J, Cahill Jr GF. Liver and kidney metabolism during prolonged starvation. J Clin Invest 1969;48:574-83.

[26] Dhatariya K, Savage M, Kelly T, Sampson M, Walden E, Walton C, et al. Joint British Diabetes Societies Inpatient Care Group. The management of diabetic ketoacidosis in adults2nd ed. ; 2013[Update: September 2013 ed].

[27] Fisher JN, Shahshahani MN, Kitabchi AE. Diabetic ketoacidosis: low-dose insulin therapy by various routes. $\mathrm{N}$ Engl J Med 1977;297:238-41.

[28] Sheikh-Ali M, Karon BS, Basu A, Kudva YC, Muller LA, Xu J, et al. Can serum beta-hydroxybutyrate be used to diagnose diabetic ketoacidosis? Diabetes Care 2008;31:643-7.

[29] Byrne HA, Tieszen KL, Hollis S, Dornan TL, New JP. Evaluation of an electrochemical sensor for measuring blood ketones. Diabetes Care 2000;23:500-3.

[30] Yu HY, Agus M, Kellogg MD. Clinical utility of Abbott precision Xceed Pro ${ }^{\circledR}$ ketone meter in diabetic patients. Pediatr Diabetes 2011;12:649-55.

[31] Noyes KJ, Crofton P, Bath LE, Holmes A, Stark L, Oxley CD, et al. Hydroxybutyrate near-patient testing to evaluate a new end-point for intravenous insulin therapy in the treatment of diabetic ketoacidosis in children. Pediatr Diabetes 2007;8: 150-6.

[32] Vanelli M, Chiari G, Capuano C. Cost effectiveness of the direct measurement of 3-beta-hydroxybutyrate in the management of diabetic ketoacidosis in children. Diabetes Care 2003;26:959.

[33] Klocker AA, Phelan H, Twigg SM, Craig ME. Blood betahydroxybutyrate vs. urine acetoacetate testing for the prevention and management of ketoacidosis in type 1 diabetes: a systematic review. Diabet Med 2013;30:818-24.

[34] Mahon WA, Holland J, Urowitz MB. Hyperosmolar, nonketotic diabetic coma. Can Med Assoc J 1968;99:1090-2.

[35] Nyenwe EA, Razavi LN, Kitabchi AE, Khan AN, Wan JY. Acidosis: the prime determinant of depressed sensorium in diabetic ketoacidosis. Diabetes Care 2010;33:1837-9.

[36] Hoorn EJ, Carlotti AP, Costa LA, MacMahon B, Bohn G, Zietse $\mathrm{R}$, et al. Preventing a drop in effective plasma osmolality to minimize the likelihood of cerebral edema during treatment of children with diabetic ketoacidosis. J Pediatr 2007;150: 467-73.

[37] Tasker RC, Acerini CL. Cerebral edema in children with diabetic ketoacidosis: vasogenic rather than cellular? Pediatr Diabetes 2014;15:261-70.

[38] Watts W, Edge JA. How can cerebral edema during treatment of diabetic ketoacidosis be avoided? Pediatr Diabetes 2014;15: 271-6.

[39] Kitabchi AE, Umpierrez GE, Murphy MB, Barrett EJ, Kreisberg RA, Malone JI, et al. Hyperglycemic crises in diabetes. Diabetes Care 2004;27(Suppl. 1):S94-102.

[40] Myburgh JA, Finfer S, Bellomo R, Billot L, Cass A, Gattas D, et al. Hydroxyethyl starch or saline for fluid resuscitation in intensive care. N Engl J Med 2012;367:1901-11.

[41] Perner A, Haase N, Guttormsen AB, Tenhunen J, Klemenzson G, Aneman A, et al. Hydroxyethyl starch 130/0.42 versus Ringer's acetate in severe sepsis. N Engl J Med 2012;367: 124-34.

[42] Zarychanski R, Abou-Setta AM, Turgeon AF, Houston BL, McIntyre L, Marshall JC, et al. Association of hydroxyethyl starch administration with mortality and acute kidney injury in critically ill patients requiring volume resuscitation: a systematic review and meta-analysis. JAMA 2013;309:678-88.

[43] Perel P, Roberts I, Ker K. Colloids versus crystalloids for fluid resuscitation in critically ill patients. Cochrane Database Syst Rev 2013;2, CD000567.

[44] Hillman K. Fluid resuscitation in diabetic emergencies-a reappraisal. Intensive Care Med 1987;13:4-8.

[45] Durward A, Ferguson LP, Taylor D, Murdoch IA, Tibby SM. The temporal relationship between glucose-corrected serum sodium and neurological status in severe diabetic ketoacidosis. Arch Dis Child 2011;96:50-7.

[46] Edge JA, Jakes RW, Roy Y, Hawkins M, Winter D, Ford-Adams ME, et al. The UK case-control study of cerebral oedema complicating diabetic ketoacidosis in children. Diabetologia 2006;49:2002-9.

[47] Kydd DM. Salt and water in the treatment of diabetic acidosis. J Clin Invest 1933;12:1169-83.

[48] Van Zyl DG, Rheeder P, Delport E. Fluid management in diabetic-acidosis--Ringer's lactate versus normal saline: a randomized controlled trial. QJM 2012;105:337-43.

[49] Wolfsdorf J, Craig ME, Daneman D, Dunger D, Edge J, Lee W, et al. Diabetic ketoacidosis in children and adolescents with diabetes. Pediatr Diabetes 2009;10(Suppl. 12):118-33.

[50] Scott A, Claydon A, Kelly T, Sampson M, Walden E, Walton C, et al. Joint British Diabetes Societies Inpatient Care Group. The management of the hyperosmolar hyperglycaemic state (HHS) in adults with diabetes; 2012, [August 2012 ed].

[51] Ennis E, Stahl E, Kreisberg R. The hyperosmolar hyperglycemic syndrome. Diabetes Rev 1994;115-26. 
[52] Adrogue HJ, Madias NE. Hypernatremia. N Engl J Med 2000; 342:1493-9.

[53] Katz MA. Hyperglycemia-induced hyponatremia-calculation of expected serum sodium depression. N Engl J Med 1973;289:843-4.

[54] Hillier TA, Abbott RD, Barrett EJ. Hyponatremia: evaluating the correction factor for hyperglycemia. Am J Med 1999;106:399-403.

[55] Alberti KGMM, Hockaday TDR, Turner RC. Small doses of intramuscular insulin in the treatment of diabetic "coma". Lancet 1973;302:515-22.

[56] Kitabchi AE, Umpierrez GE, Fisher JN, Murphy MB, Stentz FB. Thirty years of personal experience in hyperglycemic crises: diabetic ketoacidosis and hyperglycemic hyperosmolar state. J Clin Endocrinol Metab 2008;93:1541-52.

[57] Kitabchi AE, Ayyagari V, Guerra SM. The efficacy of low-dose versus conventional therapy of insulin for treatment of diabetic ketoacidosis. Ann Intern Med 1976;84:633-8.

[58] Kitabchi AE, Murphy MB, Spencer J, Matteri R, Karas J. Is a priming dose of insulin necessary in a low-dose insulin protocol for the treatment of diabetic ketoacidosis? Diabetes Care 2008;31:2081-5.

[59] Wiggam MI, O'Kane MJ, Harper R, Atkinson AB, Hadden DR, Trimble ER, et al. Treatment of diabetic ketoacidosis using normalization of blood 3-hydroxybutyrate concentration as the endpoint of emergency management. A randomized controlled study. Diabetes Care 1997;20:1347-52.

[60] Luzi L, Barrett EJ, Groop LC, Ferrannini E, DeFronzo RA. Metabolic effects of low-dose insulin therapy on glucose metabolism in diabetic ketoacidosis. Diabetes 1988;37:1470-7.

[61] Wagner A, Risse A, Brill HL, Wienhausen-Wilke V, Rottmann $\mathrm{M}$, Sondern $\mathrm{K}$, et al. Therapy of severe diabetic ketoacidosis. Zero-mortality under very-low-dose insulin application. Diabetes Care 1999;22:674-7.

[62] DeFronzo RA, Hendler R, Simonson D. Insulin resistance is a prominent feature of insulin-dependent diabetes. Diabetes 1982;31:795-801.

[63] Hsia E, Seggelke S, Gibbs J, Hawkins RM, Cohlmia E, Rasouli N, et al. Subcutaneous administration of glargine to diabetic patients receiving insulin infusion prevents rebound hyperglycemia. J Clin Endocrinol Metab 2012;97:3132-7.

[64] Shankar V, Haque A, Churchwell KB, Russell W. Insulin glargine supplementation during early management phase of diabetic ketoacidosis in children. Intensive Care Med 2007; 33:1173-8.
[65] Umpierrez GE, Jones S, Smiley D, Mulligan P, Keyler T, Temponi A, et al. Insulin analogs versus human insulin in the treatment of patients with diabetic ketoacidosis: a randomized controlled trial. Diabetes Care 2009;32:1164-9.

[66] Umpierrez GE, Latif K, Stoever J, Cuervo R, Park L, Freire AX, et al. Efficacy of subcutaneous insulin lispro versus continuous intravenous regular insulin for the treatment of patients with diabetic ketoacidosis. Am J Med 2004;117:291-6.

[67] Ersoz HO, Ukinc K, Kose M, Erem C, Gunduz A, Hacihasanoglu $A B$, et al. Subcutaneous lispro and intravenous regular insulin treatments are equally effective and safe for the treatment of mild and moderate diabetic ketoacidosis in adult patients. Int J Clin Pract 2006;60:429-33.

[68] Umpierrez GE, Cuervo R, Karabell A, Latif K, Freire AX, Kitabchi AE. Treatment of diabetic ketoacidosis with subcutaneous insulin aspart. Diabetes Care 2004;27:1873-8.

[69] Adrogue HJ, Wilson H, Boyd 3rd AE, Suki WN, Eknoyan G. Plasma acid-base patterns in diabetic ketoacidosis. N Engl J Med 1982;307:1603-10.

[70] Gibby OM, Veale KE, Hayes TM, Jones JG, Wardrop CA. Oxygen availability from the blood and the effect of phosphate replacement on erythrocyte 2,3-diphosphoglycerate and haemoglobin-oxygen affinity in diabetic ketoacidosis. Diabetologia 1978;15:381-5.

[71] Fisher JN, Kitabchi AE. A randomized study of phosphate therapy in the treatment of diabetic ketoacidosis. J Clin Endocrinol Metab 1983;57:177-80.

[72] Wilson HK, Keuer SP, Lea AS, Boyd 3rd AE, Eknoyan G. Phosphate therapy in diabetic ketoacidosis. Arch Intern Med 1982;142:517-20.

[73] Morris LR, Murphy MB, Kitabchi AE. Bicarbonate therapy in severe diabetic ketoacidosis. Ann Intern Med 1986;105: 836-40.

[74] Kamel KS, Halperin ML. Acid-base problems in diabetic ketoacidosis. N Engl J Med 2015;372:546-54.

[75] Keenan CR, Murin S, White RH. High risk for venous thromboembolism in diabetics with hyperosmolar state: comparison with other acute medical illnesses. J Thromb Haemost 2007;5:1185-90.

[76] Carr ME. Diabetes mellitus: a hypercoagulable state. J Diabetes Complications 2001;15:44-54.

[77] Wordsworth G, Robinson A, Ward A, Atkin M. HHS - full or prophylactic anticoagulation? Br J Diabetes Vasc Dis 2014;14:64-6. 